Book Review

\section{Refugee Communities}

\author{
by Steven J. Gold \\ Newbury Park: Sage, 1992
}

\section{Reviewed by John Sorenson}

Steven J. Gold's Refugee Communities offers a comparative ethnographic study of adaptation to resettlement in California on the part of two refugee groups, Soviet Jews and Vietnamese. The book is based on the author's experience as an Englishlanguage teacher and resettlement worker from 1982 to 1990 and provides a number of useful and interesting insights into the adaptation process.

The comparative approach is particularly suited to discerning the contextual aspects of adaptation and avoiding ethnocentricinterpretations of behaviour. As well, Gold rejects what he terms an artificial distinction between refugees and immigrants and, emphasizing the selfdetermining aspects of both groups, draws upon literature on migration to illuminate these communities. He suggests that previous studies of refugee adaptation have been guided more by the policyand problem-oriented approach of social services agencies than by sociological inquiry, and that this has created a literature that overemphasizes community solidarity among refugee populations. Based on his work with these two groups in California, Gold argues that ethnic mobilization and the development of ethnic communities are not inevitable for all migrants, and that refugee populations are equally likely to be characterized by diversity and fragmentation. His research depicts a lack of community-wide organization and a prevalence of informal associations at the local level. Diversity rather than ethnic solidarity emerges as the defining characteristic of both groups, although Gold does allow the possibility that such solidarity may emerge over time.

The book provides concise summaries on the background of each refugee group and describes their characteristics as enclaves in California. These chapters are accompanied by what the publisher describes as photographic essays, but the photographs themselves do not seem an integral part of the book, nor do they add very much to our understanding of either refugee group. The text, however, provides some very interesting information on internal differentiation and factionalism within each group, which does much to correct certain stereotypes of refugees.

There is diversity in both groups in terms of class, ethnic and national identity, religion, region and ideology. Gold notes that the Vietnamese group is divided into distinct subgroups and "waves": the elite South Vietnamese who came in 1975, and the "Boat People" and ethnic Chinese who came later.

While the Soviet Jews are more homogeneous, Gold finds that the community is characterized by mutual suspicion and, contrary to what might be expected, there is little development of formal organizations. Gold suggests that one explanation for this may exist in the compulsory organization that existed in the former Soviet Union, as well as a system that required one to manipulate personal connections.

One of the most important aspects of the book is the manner in which it points out the differing agendas of refugees and the various resettlement agencies that have been created to assist them. Clearly, the agencies and the refugees have different priorities in many respects. For example, Gold suggests that settlement agencies may find themselves competing for funds and try to find jobs for as many refugees as possible in a short time. Yet he finds that many Soviet Jewish refugees in particular seek higher-status jobs and resent being pushed into what they regard as menial positions. Those who have worked with refugees will recognize this as a common complaint, particularly from professionals. While it may sometimes reflect refugees' unrealistic expectations, Gold indicates that the staff of resettlement agencies may feel threatened by client autonomy and maintains that refugees should be regarded as "able partners, not dependent adversaries."

Related to this is Gold's discussion of the relationship of Soviet Jewish refugees with American Jewish groups who were active in sponsoring the refugees. He describes how a number of Jewish settlement agencies made religious indoctrination a part of their programs, such as
English language classes, while the refugees were much less interested in religion and more concerned with practical aspects of settlement. There were a number of other cultural differences between the refugees and American Jewish groups. For example, the refugees have had a more right-wing political orientation and conflicts arose because they viewed some Americans as being too soft on socialism or the Soviet Union. Unfortunately, although the mobilizing efforts of anticommunist activists among both of these refugee groups would seem to offer a natural area for comparison, Gold does not devote much attention to the important but much-neglected discussion of the politics of refugee communities.

There is, however, an interesting discussion of entrepreneurial activity on the part of refugees. Typically, the development of small businesses among immigrant communities has been explained either by cultural theories that suggest that certain groups are naturally inclined towards entrepreneurial activities, or theories that suggest that such groups go into business because they are disadvantaged and excluded from opportunities in the broader society. Gold rejects both explanations, dismissing cultural theories as tautological and finding no evidence that self-employment exists as a direct alternative to unemployment. Instead, he suggests that independence is a key motivation for immigrants to go into business for themselves. Self-employment limits contact with the unfamiliar host culture, provides employment for relatives and unique opportunities within refugee communities.

Noting that businesses have a symbioticrelationship with ethnic communities and may foster community development, Gold also discusses exploitation and paternalism within immigrant businesses and notes that entrepreneurs from both groups prefer to hire more docile Latino workers. Refugee Communities is recommended as an interesting book that will be useful to all those who seek a better understanding of the refugee experience.

\footnotetext{
John Sorenson is a research associate at the CRS and the Disaster Research Unit at the University of Manitoba.
} 